\title{
TI.14.1
}

\section{Federation Soup}

- PDF: 00013FederationSoup.pdf

- Text: 00013FederationSoup.txt

\section{More Information}

\begin{tabular}{|c|c|}
\hline Repository ID & TI.14.1 \\
\hline Persistent URL & http://doi.org/10.26869/TI.14.1 \\
\hline Title & Federation Soup \\
\hline Authors & Unknown \\
\hline Sponsor & MACE \\
\hline \multicolumn{2}{|l|}{ Review } \\
\hline Status & Legacy \\
\hline Publish Date & $9 / 7 / 2008$ \\
\hline DOI & 10.26869/TI.14.1 \\
\hline \multicolumn{2}{|l|}{ Signature } \\
\hline Deprecated & No \\
\hline \multicolumn{2}{|l|}{ Future Review } \\
\hline \multicolumn{2}{|l|}{ Supersedes } \\
\hline Format & PDF \\
\hline Related Docs & TI.15.1 \\
\hline \multicolumn{2}{|c|}{ Development Location } \\
\hline \multicolumn{2}{|l|}{ IP Framework } \\
\hline Subject Tags & middlewarerescue \\
\hline Notes & Final report from the "Federation Soup: An Assembly of Ingredients" workshop held June 2-4, 2008 \\
\hline
\end{tabular}

